\title{
DEBATES
}

\section{Política e sociedade na primeira geração cepalina: a teoria do desenvolvimento de Celso Furtado e José Medina Echavarría}

\author{
Politics and society in the first eclac generation: the development \\ theory of Celso Furtado and José Medina Echavarria
}

\section{Gustavo Louis Henrique Pinto}

\section{Resumo}

As análises da dimensão política e social presentes na teoria do desenvolvimento do estruturalismo cepalino, em sua primeira geração (1948-1960), estão marcadas pelas interpretaçôes de Celso Furtado e José Medina Echavarría. Colocamos em questão as teses e projetos destes dois pensadores, buscando analisar como autores com diferentes métodos convergiram em uma mesma esfera de debate sobre o desenvolvimento/subdesenvolvimento, que é a política, com o privilégio do tema da democracia, e a análise das estruturas sociais. Desejamos compreender as semelhanças e diferenças encontradas nestes dois autores, primeiro, no que remete à ampliação da ideia de desenvolvimento para além da dimensão econômica e, segundo, na proposição do planejamento democrático como estratégia de superação do subdesenvolvimento. A análise realizada foi das produçóes das décadas de 1950 e 1960, de modo a demonstrar o ineditismo desta dimensão ampliada do desenvolvimento presente nestes autores.

\section{Palavras-chave}

CEPAL; Celso Furtado; José Medina Echavarría; Teoria do Desenvolvimento; Pensamento Político.

\begin{abstract}
The analyses of the political and social dimension existent in the theory of development, considering ECLAC structuralism in its first generation (1948-1960) are marked by the interpretation of Celso Furtado and José Medina Echavarría. We put in discussion theses and projects of these two thinkers, trying to analyze how authors with such different methods converged in the same sphere of development/underdevelopment debate, which is politics, with the privilege of the theme democracy, and the analysis of social structures. We aim to understand the similarities and differences that are found in these two authors, first, in what refers to the expansion of the idea of development beyond the economic dimension and, secondly, in the proposition of democratic planning as a strategy to overcome underdevelopment. The analysis proceeded on productions of the 1950s and 1960s, in order to demonstrate the novelty of this enlarged development dimension present in these authors.
\end{abstract}

\section{Keywords}

ECLAC; Celso Furtado; José Medina Echavarría; Theory of Development; Political Thinking. 


\section{Introdução}

As experiências do estruturalismo latino-americano e do desenvolvimentismo ensejadas pelo pensamento produzido em torno da CEPAL - Comissão Econômica para América Latina e Caribe -, significaram um dos principais momentos de sistematização e de circulação de interpretaçóes em comum para a região, no decorrer do século XX. Ideias como subdesenvolvimento, atraso e centro-periferia são identificadas como a constituição, para alguns autores, de uma "Escola LatinoAmericana do Desenvolvimento" (DI FILIPPO, 2007), ou como teorias realmente autóctones da região (LOVE, 2011), também como teorias que constituem "ideias no lugar”, em relação à ideia de centro-periferia (CARDOSO, 1977). Enfim, a constituição de uma determinada tradição de pensamento, a escola do estruturalismo cepalino.

No pensamento cepalino, em relação à primeira geração desta instituição presente desde a sua fundação (BIELSCHOWSKY, 2000), entre 1948 e 1960, apontamos o argumento que somente o economista brasileiro Celso Furtado (19202004) e o sociólogo espanhol José Medina Echavarría (1903-1977) realizaram contribuiçôes significativas à teoria do desenvolvimento cujos aspectos políticos e sociais foram centrais na elaboração de suas argumentações a respeito da periferia. A formação da "civilização industrial" nos países latino-americanos e a possibilidade de modernização via nacional-desenvolvimentismo em vários destes países conduziram análises a respeito das variáveis não-econômicas, dos aspectos do poder político, da formação do Estado-Nação, da ação das elites, da intelligentsia, da relação entre classes sociais e dos trabalhadores. Ao todo representam temáticas que foram incorporadas à teoria do desenvolvimento da CEPAL principalmente por Furtado e Echavarría e isso significa um traço de distinção na primeira geração de cepalinos.

O primeiro objetivo aqui esboçado visa apontar a dimensão política e social como consideraçôes centrais da teoria do desenvolvimento de Furtado e Echavarría, apresentado a partir do argumento comum destes autores a respeito da inviabilidade em pensar o desenvolvimento apenas no campo econômico. A ampliação das dimensões do desenvolvimento para aspectos políticos, sociais e culturais constitui uma inovaçáo do período da década de 1950, em nível internacional, dos estudos da área da qual os dois autores, de diferentes formas, participam intensamente. Especificamente, os textos aqui comparados que permitem visualizar a defesa dos aspectos políticos e sociais do desenvolvimento são A pré-revolução brasileira (1962) e Dialética do desenvolvimento (1964), de Furtado, e Aspectos sociales del desarrollo 
económico (1959a) e Consideraciones sociológicas del desarrollo económico de América Latina (1964), de Echavarría.

A afirmação desta característica em Furtado é recorrente na literatura especializada sobre o autor (CEPÊDA, 1998; REZENDE, 2004; VIEIRA, 2007), porém, o que constitui de resultado a ser demonstrado é a comparação com Echavarría, que permite constatar que ambos os autores se preocupavam, em suas argumentações, com as relações entre o Estado e a Política, instituições e os grupos sociais, elites dirigentes e os trabalhadores. Essa afirmação aparece de modo disperso na literatura sobre a CEPAL, e necessita de sistematização junto à área do pensamento político, para melhor pensar as tradiçóes nos estudos do desenvolvimento.

O segundo objetivo é apresentar a análise de que Furtado e Echavarría foram dois, dentre a primeira geração de cepalinos, que colocaram o debate da democracia como central na proposição do planejamento democrático. A hipótese consiste olhar para o momento em que os dois autores se deparam com a questão de como construir a modernidade na periferia, desencadeando na política como espaço central nesta tarefa e, principalmente, com o peso da democracia na realização do desenvolvimento. Deste modo, apresenta uma interpretação distinta de democracia em cada autor, entendida como estratégia e conectada aos fins da política de desenvolvimento em Furtado, de base social-democrática, e como um valor de liberdade e "criação social" em Echavarría, de base liberal competitiva ${ }^{1}$.

\section{Política e mudança social na teorização do subdesenvolvimento}

A análise política do desenvolvimento econômico converge para o debate do "papel dos intelectuais" na formação do nacional-desenvolvimentismo e dos "projetos teóricos” que sustentam e legitimam as escolhas políticas de cada período. A intersecção destes problemas aparece na obra e na ação de vários autores do pensamento político latino-americano. Neste trabalho o recorte foca a análise da produção de Furtado e Echavarría por dois motivos: ambos pertenceriam à "linhagem orgânica” (papel preponderante do Estado sobre a sociedade cf. BRANDÃO, 2007) em seu momento de "racionalidade econômica" (nacional-desenvolvimentismo, cf.

\footnotetext{
1 A análise sobre a democracia em Furtado, aproximando-o do campo da socialdemocracia, está fortemente apoiada sobre a obra de Cepêda (1998), que analisou a política em Furtado, e aparece de maneira diferenciada nas obras de R. M. Vieira (2006) e W. Vieira (2010). A aproximação de Echavarría ao campo liberal foi debatida por Gurrieri (1980), Cardoso (1982) e Martín (2012).
} 
BIELSCHOWSKY, 2004). A eficácia da "racionalidade econômica” em ambos estava ancorada em pressupostos para a transformaçáo política dos países latino-americanos. A comparação sustenta um movimento de confronto entre teses que pertencem a um mesmo campo de debate (a tradição cepalina), mas tratam as categorias de análise de maneira diversa, filiam-se a distintos paradigmas teóricos e resultam em percepções políticas diversas sobre temas importantes neste debate como desenvolvimento, pacto social, planejamento e democracia.

Os intelectuais cepalinos produziram uma teorização a respeito da periferia, sendo esta uma característica que marca o conjunto da "escola de pensamento" da CEPAL, e não é, evidentemente, uma particularidade dos nossos dois autores. A diferenciação presente nas contribuições de Furtado e Echavarría às interpretações da teoria do desenvolvimento estão justamente na ampliação dos significados compreendidos na ideia de desenvolvimento. Estes dois autores, dentre a primeira geração de intelectuais cepalinos, realizaram as maiores contribuições (e talvez as únicas) à "transformação conceitual da ideia de desenvolvimento".

Passo seguro em Echavarría, que era intelectual das ciências sociais, e que adota uma crítica ao "economicismo" presente na teoria do desenvolvimento, fazendo a defesa da área da "sociologia do desenvolvimento". Entấo o desenvolvimento deve ser compreendido em sua dimensão integral, na conjugação da economia com as relaçóes sociais, culturais e políticas; passo de distinção em Furtado dentre os economistas, em que a interpretação econômica é superada por outras dimensões da realidade, especificamente a realidade social e o poder político - o "processo global, estrutural e histórico" da teoria do desenvolvimento furtadiana simboliza a dimensão ampliada da própria ideia de desenvolvimento. Verificamos tal posicionamento nas obras de Furtado e Echavarría, presente tanto nas interpretações históricas do subdesenvolvimento, principalmente na constituição do mundo rural, quanto no "projeto" político estabelecido pelas reflexões sobre o "planejamento democrático".

Nestes termos, ressaltamos a ideia de democracia na obra de Furtado, cujo tema das classes é tratado em categorias genéricas (trabalhadores, nação), e o arranjo político proposto por este autor se aproximava do campo do nacionalismo e não da competição, portanto estava longe da perspectiva democrática clássica, a representativa. Percebemos uma transição na obra de Furtado entre o período cepalino (1949-1958) e sua fase de "projeto" desenvolvimentista e ação política (1958-1964), cujo pensamento do autor se aprofundou nos diagnósticos ligados à democracia, principalmente a partir dos temas voltados aos "obstáculos" do desenvolvimento do Nordeste (em torno da SUDENE - Superintendência do 
Desenvolvimento do Nordeste) e das reformas de base (ligado ao Plano Trienal, no período 1963-1964).

Em Echavarría a literatura aponta (GURRIERI, 1980; CARDOSO, 1982; MARTÍN, 2012), diferentemente, a democracia como um imperativo na construção de um modelo de democracia liberal pluralista, o que o aproximou da temática da legitimidade do poder e do necessário estabelecimento de um regime representativo para a condução do planejamento. A tradição do liberalismo político dentro da CEPAL legado por Echavarría constitui-se uma exceção, principalmente se analisados os intelectuais reunidos no ILPES - Instituto Latinoamericano y del Caribe de Planificación Económica y Social -, nas décadas de 1960 sob a direção de Echavarría. Os temas das "inversões sociais" e "humanas" do desenvolvimento que caracterizam o pensamento de Echavarría contém um ponto de partida fundamental, que é a necessária eficácia dos valores liberais na construção das políticas de desenvolvimento e das instituições políticas na Periferia.

\section{As interpretações de Furtado e Echavarria}

Furtado assinalou, em Teoria e política do desenvolvimento econômico (1986), a respeito da composição dos parâmetros não-econômicos na teoria do desenvolvimento realizada por ele próprio e pelos estruturalistas cepalinos, e afirmou:

como esses fatores "não-econômicos" - regime de propriedade da terra, controle das empresas por grupos estrangeiros, existência de uma parte da população "fora" da economia de mercado - integram a matriz estrutural do modelo com que trabalha o economista, aqueles que deram ênfase especial ao estudo de tais parâmetros foram chamados de "estruturalistas". Em um certo sentido, o trabalho desses economistas aproxima-se do daqueles outros preocupados em dinamizar os modelos econômicos. Em um e outro casos, tem-se em vista transformar constantes em variáveis, o que permite alcançar um nível mais alto de generalidade no esforço de teorização. Considerado o problema sobre outro aspecto, os estruturalistas retomaram a tradição do pensamento marxista, na medida em que este último colocou em primeiro plano a análise das estruturas sociais como meio para compreender o comportamento das variáveis econômicas (FURTADO, 1986, p. 72-73).

Os desequilíbrios internos e externos, o aumento populacional, o impacto da renda sobre o conjunto da população, são consideraçóes fundamentais no modelo de Furtado, e que levam em conta as estruturas sociais da periferia. A teoria de fundação 
84 | Gustavo Louis Henrique Pinto

do estruturalismo cepalino (centro-periferia) foi posta à prova pela crítica dos próprios cepalinos, frente a outros campos do conhecimento do que somente o econômico, possibilitando identificar um deslocamento para novas temáticas sociais e políticas.

A fase de Furtado que compreende entre 1958 e 1964, que foi fase pósparticipação na CEPAL (participação que perdurou entre 1949 e 1958), está representada na trajetória de Furtado principalmente pelo projeto da SUDENE e as "reformas de base" no Plano Trienal, em 1963, como Ministro do Planejamento no governo de João Goulart (1961-1964). Esse momento do "projeto político" de Furtado foi de aprofundamento de uma posição reformista, cujas estratégias de desenvolvimento (SUDENE e as "reformas de base") estiveram fortemente vinculadas à interpretação do desenvolvimento em uma perspectiva "integral". Os trabalhos de Furtado A pré-revolução brasileira (1962) e Dialética do desenvolvimento (1964) apresentam esse argumento político a respeito do protagonismo da ação do Estado frente as "reformas de base" (como uma etapa para a modernização do Nordeste principalmente) e significa também a consolidação da tese de Furtado referente aos obstáculos político-econômicos que a estrutura agrária conferia ao "desenvolvimentismo", já que esta estrutura reproduzia o dualismo estrutural e impedia a mobilidade social dos estratos rurais.

As contravenções na formulação e implementação da SUDENE e a luta política de Furtado enquanto Superintendente desta instituição foram fatos fundamentais na formulação, por este autor, do que este intitulava por uma "filosofia da ação". A pré-revolução brasileira (1962) foi o esforço de Furtado para demonstrar que no considerado estágio de desenvolvimento brasileiro, a sociedade civil - quanto aos seus "tomadores de decisão" em prol do desenvolvimento -, tinha que assegurar o controle dos centros políticos de decisão, o que significava “(...) tomar consciência plena dos objetivos de nossa ação política em função do nosso próprio destino de povo e cultura" (FURTADO, 1962, p. 19). A consciência em torno do desenvolvimento tinha que afastar a falsa alternativa entre a liberdade versus o desenvolvimento econômico rápido, já que a liberdade de uma minoria constituía para Furtado o sacrifício do bem-estar das "grandes maiorias". O desenvolvimento material das forças produtivas não se trata de uma realidade por si só suficiente, pois no subdesenvolvimento este processo vem acompanhado por uma rigidez nas formas de organização político-sociais. A radicalização do pensamento reformista de Furtado estava presente na proposição de acelerar as transformaçóes sociais e garantir uma sociedade aberta em pleno desenvolvimento e com enlace democrático (econômico, 
social, político, cultural), de maneira que afastasse uma possível saída revolucionária "marxista-leninista". As rupturas revolucionárias dificultariam os objetivos sociais do desenvolvimento com planejamento democrático e seriam atingidos por uma "ruptura cataclísmica", ou através de processos de endurecimento político e contenção dos objetivos sociais através da força. A respeito das pressões sociais Furtado afirma:

o problema fundamental que se apresenta é, portanto, desenvolver técnicas que permitam alcançar rápidas transformaçôes sociais com os padrốes de convivência humana de uma sociedade aberta. Se não lograrmos esse objetivo, a alternativa não será o imobilismo, pois as pressóes sociais abrirão caminho, escapando a toda possibilidade de previsão e controle (FURTADO, 1962, p. 26).

Tratava-se de elaborar objetivos para o desenvolvimento conduzido com verdadeiro "critério social". As pressôes podiam desencadear "golpes preventivos" ou soluções de emergência (daí o título do livro "a pré-revolução"), então a solução seria romper com o latente retrocesso do sistema político e realizar a reforma agrária. $A$ pré-revolução brasileira foi o primeiro texto de Furtado com uma defesa explícita da "reforma agrária", pensada como parte de uma política que subordinasse essa reforma ao desenvolvimento econômico e social. O sistema político torna-se o centro do diagnóstico de Furtado e organiza-se na percepção de que uma política de desenvolvimento em um país subdesenvolvido é de natureza sempre qualitativa.

A necessidade de "reformas de base" se expressava nos "desajustamentos estruturais" do plano político e foi posicionada como uma espécie de tomada de consciência. Furtado assim afirmou sobre as "reformas de base" que "tratam-se, evidentemente, de reivindicaçóes ou recomendações que traduzem uma tomada de consciência de problemas estruturais, portanto de natureza essencialmente qualitativa" (FURTADO, 1962, p. 39). O êxito logrado sobre os "fins" de uma política (econômica) do desenvolvimento dependiam do grau de racionalidade política e dos valores nos "meios" adotados. A SUDENE era a possibilidade para Furtado de realizar uma ação técnica com comando político, uma instituição que tinha por idealização a unidade entre a técnica e a dimensão social, já que o desenvolvimento significava, para Furtado, um esforço da coletividade. "A luta pelo desenvolvimento é também uma luta pela racionalidade na política, pois somente superando as mitologias ideológicas se pode evitar o domínio do povo por demagogos 
e aventureiros" (FURTADO, 1962, p. 63). Esta "tomada de consciência" presente em 1962, constitui parte da "responsabilidade" sobre as forças históricas profundas das mudanças em processo na realidade, que poderiam entrar em choque caso a capacidade política (a "consciência”) para mudar não agisse sobre os problemas do subdesenvolvimento.

Se as funções do Estado, afirma Furtado (1962), não estão vinculadas aos objetivos de um desenvolvimento via planejamento, e diante do "anacronismo" do aparelho de administração pública, tem como consequência um Estado que não reúne condições para se constituir em agente central de "luta pelo desenvolvimento". É interessante o argumento apresentado por Furtado de que em sociedades de elevada diferenciação social como o Brasil, as relações sociais que são diretamente impactadas pela ação do Estado - como os elementos da "convivência social", da distribuição de renda, de impacto fiscal - não podem estar subordinadas aos critérios do desenvolvimento econômico, mas sim do desenvolvimento social. Furtado afirma a este respeito:

não se pode desconhecer que, em um país subdesenvolvido, os aspectos econômicos do desenvolvimento social assumem grande emergência. Não é possível educar os homens sem antes lhe matar a fome. Contudo, relegar a segundo plano outros aspectos do problema social seria comprometer o desenvolvimento subsequente da cultura que deverá moldar o homem do futuro (FURTADO, 1962, p. 91).

Os objetivos de uma política econômica para o desenvolvimento sempre estiveram presentes no pensamento cepalino, porém o impacto da mudança social é mais do que uma incorporação de novos critérios, mas uma condição para o desenvolvimento. O campo de forças do projeto desenvolvimentista se fortalece na ação política de resolução dos problemas sociais. O planejamento democrático assim se delineou, em que o aprofundamento da democracia somente era possível, para Furtado, com esforço da coletividade, que teria a capacidade de orientar políticas de desenvolvimento econômico com mudanças sociais.

A proposição da construção de modelos e a defesa dos instrumentos de planejamento realizados por Furtado especificamente na década de 1950, reforçam a presença do Estado na capacidade e direção dos investimentos, um posicionamento do intelectual que constituiu divergência central nas relaçôes internas da CEPAL, conforme apontamos desde o início, divergência que também proporcionou diferentes caminhos do planejamento no próprio Brasil, e reforçou o campo do 
planejamento democrático. Há uma cisão na CEPAL entre os anos de 1953 e 1954, e que se desenha ao longo da década, entre monetaristas e estruturalistas na qual o próprio Furtado se refere em A fantasia organizada (1997a). A questão deste período, demonstra a formação de um grupo de estruturalistas reformistas que se delineava dentro da CEPAL, e foi apresentada por Furtado em sua autobiografia (1997a), quando o autor analisou a recepção que seu livro $A$ economia brasileira (1954) teve na CEPAL e na ONU, gerando forte reação interna de crítica negativa sobre um livro que, para o próprio Furtado (1997a), pensava sobre as "opções" das "ações ou omissóes dos centros de decisão sob controle governamental", assim como a "natureza da planificação".

Outra importante consideração de Furtado sobre o livro de 1954, é que lá estava um estudo da inflação, que "importava acima de tudo que identificássemos as forças sociais que estavam pressionando para modificar a distribuição de renda, e descobríssemos suas motivações" (FURTADO, 1997a, p. 300). Novamente é o reforço por parte de Furtado do Estado a frente dos investimentos e, conforme afirma Bielschowsky carrega o "princípio de que a superação do subdesenvolvimento requer uma decidida intervenção planificadora por parte do Estado" (BIELSCHOWSKY, 2004, p. 152).

O "planejamento democrático" presente no pensamento de Furtado, como demonstrado até o momento, foi uma defesa que marcou posicionamento internamente na CEPAL, assim como representa um "projeto político" quanto ao contexto histórico brasileiro, com a SUDENE e o Plano Trienal na década de 1960. Afirmamos que a defesa da democracia como condição do "planejamento", conforme Furtado realizou, que vinculou democracia e planejamento, foi atenuada com o Golpe Civil-Militar no Brasil, em 1964, quando no exílio Furtado debateu os "obstáculos políticos e sociais" ao desenvolvimento, temática apresentada em Subdesenvolvimento e estagnação na América Latina (1966). Parte fundamental da argumentação sobre a estagnação, em Furtado (1966), encontra-se no esgotamento do processo democrático com o Golpe dos militares no Brasil.

Furtado aborda, principalmente nos textos até 1964, sobre o mecanismo da "tomada de consciência" por parte da intelligentsia em duas direções, que foram assinaladas em A pré-revolução brasileira (1962): não resta outra saída senão "auto dirigir-nos", ao injetar elementos de racionalidade nos instrumentos e nos "juízos de valor" das políticas de desenvolvimento. Os temores expressos por Furtado, em 1962, conferem vitalidade ao título, $A$ pré-revolução brasileira, cujo medo era dos conflitos 
sociais aprofundados paralelamente ao desenvolvimento industrial, desigualdades que poderiam instigar forças políticas e econômicas conservadoras em detrimento do processo de desenvolvimento econômico que vigorava com intensidade.

A pergunta estruturalista que persegue os projetos de desenvolvimento e as intervenções que visam algum tipo de aceleração econômica é sobre o "custo social" deste desenvolvimento e quais são os grupos privilegiados e os que sofrem os malogros de tal processo. Diante deste questionamento realizado diversas vezes por Furtado, ele também se propõe a debater a partir da relação entre os fins e os meios de qualquer política econômica. Há uma comparação comum em grande parte da literatura do desenvolvimento, principalmente estadunidense, que reside na percepção do desenvolvimento do modelo soviético como um exemplo de desenvolvimento material em detrimento da liberdade. Furtado também debate as impossibilidades, como os autores citados, do marxismo-leninismo no projeto desenvolvimentista. À comparação se soma a principal defesa de Furtado, do planejamento democrático" como forma "superior" de desenvolvimento, modelo somente possível se fruto da ação de uma verdadeira intelligentsia.

Vianna (2004) afirma a respeito do papel que a ideia de intelligentsia, assim como definida por Mannheim (1961), teve na consolidação das ciências sociais no Brasil, e que cabe ao problema aqui levantado:

a comunidade científica deve, então, intervir, e é dela que a sociedade deve esperar a "síntese total" que capta o sentido de seu movimento e a orientação em geral para o caminho que deve perseguir sob a iluminação do conhecimento produzido pela ciência social. A comunidade científica converte-se, pois, em uma intelligentsia, mas sem abdicar da construção de sua identidade específica e consequente institucionalização de sua atividade (VIANNA, 2004, p. 208).

A perspectiva ampliada de desenvolvimento de Furtado, que não significa somente um desenvolvimento material, mas do próprio homem, se relacionam com a concepção de que os fins do desenvolvimento não podem ser uma justificativa para a aplicação de "meios" que signifiquem a restrição da liberdade. Os "meios" de qualquer política no subdesenvolvimento devem sempre vislumbrar como fim a eliminação do caráter anti-humano do desenvolvimento. Furtado relaciona os "meios" de uma política econômica com a consciência política sobre os "fins" por parte daqueles que realizam a ação. 
A democracia se associa aqui a um ponto de vista humanístico do desenvolvimento, expresso na possibilidade de domínio das forças que impelem a sociedade em determinadas direçôes. A "luta" pelo desenvolvimento (o "domínio do mundo exterior") tem como "fim" as potencialidades do próprio homem. A crítica de Furtado foi endereçada diretamente ao modelo soviético, como um modelo que pode restringir a liberdade.

Vianna (2004) analisa no que constituía esta "síntese" da sociedade, à qual essa intelligentsia teria a responsabilidade em realizar, bem como a capacidade e que também foi apontado por Furtado. Vianna diz a respeito:

mas a ideia de síntese que orienta essa intelligentsia não aponta para o universo das polarizaçóes e das superaçóes dialéticas. Sobretudo, o seu ponto de vista não é o de um ator revolucionário, mas o da Ciência Social, que, captando, por meio da intervenção de recursos científicos, o sentido do movimento da sociedade, generaliza seu conhecimento a todos os atores políticos e sociais, capacitando-os a uma compreensão de alcance bem maior do que a formulada por eles enquanto identidades parciais e fragmentárias (MANNHEIM, 1976) ${ }^{2}$. Essa intelligentsia não se move no terreno da revolução, e sim no da reforma, identificando-se tacitamente com o que se pode designar como processo transformista em chave positiva, no que, aliás, reitera o viés do ensaísmo das antigas elites intelectuais (VIANNA, 2004, p. 209).

O intelectual não estaria acima das classes sociais para Furtado, seguindo Mannheim, mas entre as classes. O significado da síntese explicativa da intelligentsia está na tradução dos complexos sociais, dos valores, e se trata de uma interpretação do mundo. Qual o papel desta síntese? Associar o conhecimento racional - o entendimento dos complexos ideacionais - à responsabilidade sobre os processos políticos e sociais. Furtado (1972) afirmava a existência de uma ruptura entre um conhecimento científico e um conhecimento ideológico e a técnica social que formulava o planejamento está unida ao conhecimento científico da realidade. Rezende (2004) argumenta que a própria relação entre o pensamento e a ação na forma das técnicas sociais constitui uma posição ideológica de Furtado. Rezende (2004) também esclarece que o elemento utópico era também ideologia em

\footnotetext{
${ }^{2}$ A obra de referência é MANNHEIM, Karl. Ideologia e utopia, 3a ed., Rio de Janeiro, Zahar. 1976.
} 
Mannheim, cujas forças que impulsionam a sociedade adiante poderiam ser interceptadas por racionalidades que concebiam a mudança.

A introdução de Furtado em A dialética do desenvolvimento (1964) é a expressão do papel que o autor atribui à intelligentsia, e podemos identificar as relações com os planos da racionalidade e as classes sociais:

a responsabilidade dos intelectuais em nenhuma época foi tấo grande como no presente. E essa responsabilidade vem sendo traída pela ação de uns e a omissão de outros. (...) Não se pretende que exista uma moral dos intelectuais por cima de quaisquer escalas de valores, as quais estão necessariamente inseridas nalgum contexto social. Mas, não se pode desconhecer que o intelectual tem uma responsabilidade social particular, sendo como é o único elemento dentro de uma sociedade que não somente pode, mas deve sobrepor-se aos condicionantes sociais mais imediatos do comportamento individual. Isto lhe faculta mover-se num plano de racionalidade mais elevado e lhe outorga uma responsabilidade toda especial: a da inteligência. Porque tem essa responsabilidade, o intelectual não se pode negar a ver mais longe do que lhe facultam as lealdades de grupo e as vinculaçóes de cultura. Seu compromisso supremo é com a dignidade da pessoa humana - atributo inalienável do ser do intelectual (FURTADO, 1964, p. 9-10).

$\mathrm{O}$ argumento de Furtado sobre o intelectual, primeiro, contém um afastamento dos grupos políticos que acenavam para os radicalismos da direita e da esquerda e, segundo, uma defesa do intelectual e do plano de racionalidade "mais elevado". O afastamento é resultado político da posição estratégica de Furtado a frente do projeto da SUDENE, entre 1958 e 1962, e a função de Ministro do Planejamento, entre 1962 e 1963, de se desvincular tanto de uma direita latifundiária e oligarca quanto dos grupos da esquerda marxista. A defesa ideológica desta postura está na responsabilidade que Furtado atribuiu à inteligência, do dever do intelectual de pensar além das lealdades de grupo, de agir em um plano de racionalidade que possa antever os atos "irracionais". A racionalidade está voltada para a ação do intelectual no terreno da política. Estes cientistas sociais que deveriam ser a "salvaguarda do interesse público" não cumpriam seu devido papel. Lima (2008) afirma sobre a influência de Mannheim em Furtado contida na ideia do afastamento necessário que o intelectual deveria ter dos partidos políticos, de modo a manter uma posição "flexível" nos termos de Mannheim. 
A amplitude dos campos de pesquisa para as áreas das ciências sociais, a sociologia e a política principalmente, com impacto na Teoria do Desenvolvimento da CEPAL, esteve ligada diretamente a ação programática de Echavarría como sociólogo. Furtado foi um intérprete do desenvolvimento que incorporou as ciências sociais desde o princípio, com referências a estes aspectos já presentes na sua tese de doutorado (FURTADO, 2001 [1948]). Echavarría se diferencia de Furtado, pela atuação do espanhol na consolidação da sociologia do desenvolvimento latinoamericano. Echavarría foi incorporado à CEPAL em 1952, trabalhando inicialmente como corretor de ediçóes. Entre 1955 e 1958, Echavarría apresenta quatro trabalhos ${ }^{3}$ fundamentais de análise sociológica do desenvolvimento onde, segundo Martín, "encontramos motivos empíricos más que suficientes para poder afirmar que estamos ante un momento de creación teórica y epistemológica” (MARTÍN, 2012, p. 502) e, portanto, trata-se de um momento de fundação do campo sociológico ligado ao desenvolvimento.

No trabalho Las condiciones sociales del desarrollo económico (ECHAVARRÍA, 1959c [1955]), apresentado no Sexto Período de Sesiones de la CEPAL, 1959, em Bogotá, Colômbia, o autor propóe um conjunto de novas necessidades à investigação da teoria do desenvolvimento. A pesquisa social foi apresentada pela capacidade de oferecer novas possibilidades diante de problemas cujas análises econômicas não dariam conta, que extrapolam "las fronteras de la preocupación habitual del economista y de sus instrumentos conceptuales". Echavarría indica a necessidade de se vincular à formação do economista, a análise da estrutura social, e assim afirma:

los motivos, las actividades y las creencias que mueven a los hombres no se dan en el vacío, sino como exigencias de definidos usos e instituciones. El análisis de los motivos lleva de modo necesario al análisis de una estructura social y ésta es ya una cuestión notoriamente próxima a las preocupaciones y formación corriente del economista (ECHAVARRÍA, 1959c, p. 35).

A interdependência estabelecida por Echavarría entre a análise da estrutura social e as preocupaçóes do economista guia no sentido da qualificaçáo do que este autor compreende por estrutura social, significação que está na natureza da ciência

${ }^{3}$ Estes artigos foram publicados com o sugestivo título de Aspectos sociales del desarrollo económico (1959a). 
social realizada por este autor e, portanto, está na base de investigação da sua teoria do desenvolvimento. Vejamos o que Echavarría afirma a respeito:

ahora bien, entre los principios generales de la ciencia social contemporánea apenas nadie niega su reconocimiento a estos dos fundamentales: primero, que estructura social y carácter - como hoy se dice - se corresponden estrechamente, siendo el uno correlato del otro; segundo, que la estructura social es un complejo de instituciones que no puede alterarse sin modificaciones paralelas y más o menos profundas en todas ellas. Esto quiere decir que cuando el economista tropieza con manifestaciones de conducta que no corresponden a sus supuestos y exigencias, es que está ante un carácter - un sistema de actitudes y motivos - que fue moldeado por una estructura distinta de la que él pretende y necesita. Y que cuando, por la aspiración del desarrollo, trata de introducir en un país los instrumentos necesarios para su crecimiento económico, lo que hace es insertar factores de cambio en una institución que sólo pueden operar con éxito completo si los demás componentes de la estructura social se modifican en una dirección paralela (ECHAVARRÍA, 1959c, p. 35).

$\mathrm{O}$ autor demonstra que mudanças estruturais em sociedades pouco desenvolvidas somente são possíveis se acompanhadas de uma transformação da estrutura social e de suas instituiçóes. Pensar a teoria do desenvolvimento, bem como o próprio processo de desenvolvimento (e suas políticas) que marcaram muitos países latino-americanos na década de 1950 , somente se organizadas em conjunto com as determinantes das estruturas sociais. Os modelos e conceitos do universo econômico da teoria do desenvolvimento vão ao encontro das estruturas sociais. A identificação e conceituação das estruturas sociais compóem a identificação dos problemas para o crescimento e das políticas de desenvolvimento.

No trabalho El papel del sociólogo en las tareas del desarrollo econômico (1959b [1958]), Echavarría apresenta as possibilidades de ação da sociologia concreta sobre o desenvolvimento: a sociologia poderia trabalhar para a construção de modelos, como os economistas ou examinar as consequências sociais dos distintos ritmos de desenvolvimento. O autor aponta, seguindo de perto as análises de B. F. Hoselitz, a necessidade de se construir para além de modelos gerais, mas a sociologia poderia criar tipologias que abarcassem as "diferentes unidades históricas", incorporando a variedade de experiências dos países em vias de desenvolvimento. 
O desenvolvimento, para Echavarría (1959b), é uma "consciência generalizada" diante de seu "caráter necessário", uma tendência mundial do seu tempo. A tarefa dos modelos e tipologias, tanto da economia quanto da sociologia, era perceber as regularidades marcadas historicamente. $\mathrm{O}$ autor se restringe à área da sociologia e afirma:

(...) la tipología que aquí se postula desde la perspectiva del sociólogo, consistiría en tratar de proyectar las distintas posibilidades del desarrollo sobre la base de determinadas estructuras sociales típicas y a partir de sus distintos niveles históricos bien definidos (ECHAVARRÍA, 1959b, p. 26).

Como realizar a tarefa de identificar as possibilidades de desenvolvimento periférico, a partir de estruturas sociais típicas e historicamente condicionadas? Em termos da ação de Echavarría, este cumpriu um papel ímpar em tal tarefa; quando esteve à frente da "División de Asuntos Sociales" da CEPAL, e depois no ILPES, desempenhou um importante papel na produção de conhecimento e de políticas para o desenvolvimento. A vinculação de Echavarría com a temática do desenvolvimento foi fortemente motivada pelos cargos ocupados na CEPAL, o que configurou a projeção internacional deste sociólogo, e foi central na institucionalização da sociologia do desenvolvimento como área preponderante desde a década de 1960 nas ciências sociais latino-americanas.

Echavarría coordenou o primeiro diagnóstico dos fatores sociais do desenvolvimento produzido em nome da CEPAL, intitulado El desarrollo social de América Latina en la post-guerra (CEPAL, 1963). Este último estudo foi preparado em colaboração com Luis Ratinoff e Enzo Falleto, sendo apresentado no Décimo Período de Sesiones da CEPAL, em 1963, Mar del Plata, Argentina, momento que representou uma importante guinada sobre as interpretaçóes do campo cepalino. $\mathrm{O}$ livro de Echavarría, Consideraciones sociológicas sobre el desarrollo económico de América Latina (1964), que marca a consolidação intelectual deste autor na sociologia do desenvolvimento, refere-se também a um posicionamento dele nestas sessóes da CEPAL de 1963. Os debates das sessões da CEPAL daquele ano foram marcados pela reflexão dos rumos desta instituição conforme testemunhou o próprio Furtado (1997b) e o peso do desenvolvimento social foi sobressalente, modificando os rumos da CEPAL. O documento produzido sob a direção de Echavarría (CEPAL, 1963) foi 
recebido com profundo impacto entre os cepalinos e demonstra a importância estratégica que tinha a defesa da investigação social sobre o tema do desenvolvimento.

O enfrentamento constante de Echavarría com os métodos de análise de base econômica abarca uma recepção da sociologia na perspectiva do planejamento. $\mathrm{O}$ recém-criado ILPES, em 1963, no qual Echavarría é incorporado no mesmo ano reuniu em torno deste sociólogo uma nova geração de intelectuais da CEPAL, como Enzo Faletto, Osvaldo Sunkel, Fernando H. Cardoso, Vilmar Faria, Pedro Paz, José Serra, Francisco Weffort, Hélio Jaguaribe, José Luís Reyna, Adolfo Gurrieri, Marshall Wolfe, Aldo Solari e Rolando Franco. Encontram-se também aí os elementos formadores da sociologia do desenvolvimento, lugar também fundamental para a produção da Teoria da Dependência de enorme impacto na região. Martín (2012) ponderou que a posição ocupada por Echavarría no ILPES, de diretor à frente da División de Planificación Social entre 1963 e 1974, está conectada à institucionalização da sociologia do desenvolvimento, de enfoque histórico-estrutural (de afirmação do campo cepalino), além de também significar um traço de distinção na biografia de Echavarría, momento de reconhecimento do sociólogo espanhol enquanto figura intelectual, considerada a etapa de "maior atividade e prestígio" intelectual e de circulação internacional.

As questóes fundamentais do desenvolvimento a partir do ponto de vista social, segundo os apontamentos de Echavarría, consistem em analisar "las condiciones sociales del desarrollo económico y los efectos sociales de ese mismo desarrollo" (ECHAVARRÍA, 1959c, p. 44). Entre as duas possibilidades de investigação, Echavarría apresentou seu programa weberiano de interpretação do subdesenvolvimento, que marcou a direção dos seus primeiros trabalhos no ILPES em torno da questão do empresário e das elites na América Latina. O autor afirmou:

todo lo que, con distintos giros, se dijo acerca de la actividad económica en sus relaciones con los caracteres y motivaciones humanos y con los usos, tradiciones y vigencias de una sociedad, equivalía a plantear en forma inversa, y a veces puramente descriptiva, el tema que hizo clásico la investigación weberiana con referencia al capitalismo. ¿Cuáles son las condiciones sociales que hacen posible el funcionamiento de este sistema? Reiterar la misma pregunta desde el punto de vista del desarrollo económico de nuestros días supone una tradición de rigurosa precisión conceptual (ECHAVARRÍA, 1959c, p. 44-45). 
Estas condiçóes sociais questionadas por Echavarría, que operam no sistema do capitalismo subdesenvolvido, significava uma tarefa para uma geração. Furtado, entre os economistas cepalinos da primeira geração, foi dos poucos que apontou a interdependência entre os fatores político-sociais e os econômicos, e a relação determinante entre a democracia e o desenvolvimento. A análise das características políticas e sociais do desenvolvimento realizadas por Echavarría empreende a possibilidade do "planejamento democrático" como finalidade estratégica do desenvolvimento. Aqui reside outra comparação fundamental com Furtado, pois demonstra a similaridade destes autores na composição do paradigma democrático como central ao planejamento. E por se tratar do "planejamento democrático", traz outra vinculação com Furtado, que é o planejamento aos termos de Mannheim empenhado pelos dois autores. Interessante como Echavarría e Furtado chegam ao tema da democracia e do "planejamento democrático" a partir de trajetória distintas, de diferentes áreas do conhecimento - a sociologia em Echavarría, e a economia em Furtado -, o que também assegura que as perspectivas sobre o planejamento e sobre quais grupos deveriam se emprenhar nesta condução sejam distintas.

Segundo Echavarría, o "planejamento democrático" é uma atitude que extrapola as técnicas econômicas e se trata de uma "nova atitude espiritual do homem”. O planejamento foi então delimitado por Echavarría (1967a) como uma "atitude" primeira e uma subsequente capacidade de "racionalização efetiva". O processo de desenvolvimento impulsionado por políticas de planejamento somente tem eficácia e é legítima na medida em que expressa vínculos com o processo de "racionalização", em seus diferentes níveis, desde a liberdade dos indivíduos, até as formas de burocracia e tecnocracia, bem como o próprio crescimento econômico. Desejamos explorar essa articulação fundamental entre racionalização e planejamento, argumentação central no projeto de Echavarría.

Em Consideraciones sociológicas del desarrollo económico de América Latina (1964), há uma apresentação de Mannheim como o teórico do "planejamento democrático" e Echavarría afirma que pouco se avançou nesta temática, principalmente na América Latina. Mannheim foi posicionado como o "terceiro caminho", o da "planificação para a liberdade", em contraposição ao planejamento soviético e ao liberalismo, constituindo o caminho da "democracia militante". A concepção de um planejamento que visa o valor fundamental da liberdade é estruturante das relaçóes entre planejamento e democracia. O modelo de Mannheim é apresentado como base para pensar o planejamento democrático, principalmente os 
argumentos de Mannheim presentes no seu trabalho Diagnósticos do nosso tempo (1961), obra traduzida para o castelhano em 1944 pelo próprio Echavarría, através da editora Fondo de Cultura Económica.

Echavarría analisou a força da sociologia empenhada por Mannheim para realizar as tarefas do planejamento voltadas para a realidade latino-americana, no seu trabalho La planeación en las formas de la racionalidad (ECHAVARRÍA, 1972). O "planejamento democrático" de Mannheim era uma antípoda ao planejamento que visava somente a aceleração do crescimento econômico, mesmo em um cenário de instabilidade política. O planejamento sem o objetivo democrático e que náo incorpora uma dimensão integral do desenvolvimento, está fadado a naufragar, segundo Echavarría. A contribuição de Mannheim possuía, para Echavarría (1972), três concepçôes fundamentais sobre o planejamento: a primeira, a planificação é um "esforço de transformação total", incluindo neste propósito "o pensamento mesmo e com ele a configuração psicológica da pessoa"; a segunda, em conexão direta com a primeira, é a consideração de Mannheim de que o planejamento "exigia uma forma nova de pensamento e um novo tipo de homem"; a terceira foi considerada por Echavarría como uma "radical e violenta novidade", pois Mannheim pensava o planejamento em uma democracia liberal e representativa, cujo objetivo é a liberdade.

A defesa do liberalismo aparece como unificador desta concepção de participação efetiva. Somente as sociedades de democracia pluralista teriam condiçôes de "salvar" a ideia de "liberdade clássica", segundo o autor, presente no "pensamento liberal clássico". Echavarría (1964) afirmou que a "democracia pluralista" é a forma moderna de "equilibrar" a racionalidade econômica e a racionalidade política, e a mais próxima do planejamento democrático. A economia liberal, conforme o autor aponta em Las relaciones entre las instituciones sociales y económicas (ECHAVARRÍA, 1967b), foi uma forma de conciliação da racionalidade econômica com a racionalidade política e foi a "subordinação da razão política à razão econômica". Na economia liberal prevaleciam as racionalidades que operavam sobre um sistema econômico conforme idealizado por Weber (2000), como um sistema "formal" puro que, segundo Echavarría, prevaleceu características como o cálculo econômico, a liberdade de mercado e o sistema representativo do século XIX. As alterações profundas das condiçóes que favoreciam o funcionamento deste sistema econômico liberal, que prevalecia a racionalidade formal, representaram no século XX, para Echavarría, duas novas formas de "equilibrar" a racionalidade econômica e a racionalidade política, sendo estas formas a "democracia pluralista" e o "totalitarismo". 
O planejamento democrático foi delimitado por Echavarría (1972) através das formas do sistema representativo pluripartidário, dos mecanismos de participação e o acesso à informação e ao conhecimento, como condições para a plena eficácia da democracia. O planejamento é a racionalização do conjunto de interesses de diferentes grupos, bem como o sistema representativo, que também tenta articular diferentes opções. Desta maneira, Echavarría estabelece uma interdependência entre o planejamento democrático e o sistema representativo, cujo funcionamento de um sistema representativo partidário em termos democráticos era condição para a realizaçáo do planejamento democrático.

Como vimos até aqui, políticas de desenvolvimento empreendidas pelo planejamento, para Echavarría, somente tende à eficácia e a legitimidade em sociedades democráticas e pluralistas. A legitimidade de uma política de planejamento que converge inversões econômicas com inversôes sociais tem por objetivo a liberdade e a emancipação humana. As relações entre desenvolvimento e democracia aprofundam a participação democrática, em que as elites dirigentes e o poder político são legítimos na condução da política de desenvolvimento. $\mathrm{O}$ objetivo, a forma de uma utopia expressa por Echavarría, é o indivíduo autônomo, com liberdade de ação e de criação. No desenvolvimento, como a enunciação da nova civilização, o valor mais importante é a liberdade.

\section{Conclusão}

Afirmamos que Furtado e Echavarría são dois dos intelectuais cujas interpretações e a ação política significam atuações que estão no mesmo campo "reformista" do estruturalismo cepalino, que resistiram enquanto "projeto" e sobreviveram como interpretação de forma paralela durante a década de 1960, além de estarem presentes como influências fundamentais nas novas teorias e na revisão do estruturalismo cepalino no pós-1964, advindas com a Teoria da Dependência e dos "estilos" de desenvolvimento. Ainda mais, são as duas grandes pontes de permanência no campo cepalino do "planejamento democrático" como visão estratégica de políticas de desenvolvimento na década de 1960. Isso só é possível pois ambos empreenderam visão ampliada do desenvolvimento (econômico, social e político), possuíam uma interpretaçáo histórico-estrutural do subdesenvolvimento e defenderam abertamente a democracia como paradigma fundamental. Interessa assinalar defesa do "planejamento democrático" de Furtado e Echavarría como uma 
força na constituição da via "reformista" do estruturalismo cepalino nas décadas de 1950 e 1960.

Identificamos duas importantes confluências entre os trabalhos e as trajetórias de Furtado e Echavarría, momentos estes historicamente determinados e de formulação fundamental para o estruturalismo cepalino, e que delineiam essa via "reformista". A primeira confluência (a.) é que, de ângulos distintos, Furtado e Echavarría reforçam a atuaçáo e defesa do "planejamento democrático" como estratégia de desenvolvimento a partir de uma perspectiva "democrática" e ampliada, de forte influência de Mannheim na legitimação da ideia de "planejamento democrático". Em Furtado, apontamos as formulações de políticas de desenvolvimento empreendidas na SUDENE e nas "reformas de base" presentes no Plano Trienal, como experiências de Furtado pós-CEPAL (1958-1964), e que foram de profundo impacto nacional e internacional; Echavarría, foi protagonista da sociologia do desenvolvimento na CEPAL e representa parte fundamental da defesa de amplitude nos temas do planejamento e do desenvolvimento para as ciências sociais - e consequentemente se amplia para os temas das estruturas sociais e das instituições políticas. Retomá-los nesta perspectiva interessa para compreender um mosaico dos diversos lugares da teoria do desenvolvimento e da condição de subdesenvolvimento na América Latina.

Gustavo Louis Henrique Pinto é Doutor em Ciência Politica, pela Universidade Federal de São Carlos (UFSCar), Membro do Grupo de Pesquisa (UFSCar/CNPQ) "Trajetórias do Desenvolvimento e da Democracia”. E Professor do Instituto Federal de Educação, Ciência e Tecnologia de Goiás (IFG). E-mail: gulhpinto@gmail.com.

\section{Referências}

BIELSCHOWSKY, Ricardo. Cinquenta anos de pensamento na CEPAL: uma resenha. In:

(Org.). Cinquenta anos de pensamento na CEPAL. Rio de Janeiro: Record, 2000. p. 13-68.

. Pensamento Econômico Brasileiro: o ciclo ideológico do desenvolvimentismo. Rio de Janeiro:

Contraponto, 2004.

BRANDÃO, Gildo Marçal. Linhagens do pensamento político brasileiro. São Paulo: Hucitec, 2007. 
CARDOSO, Fernando Henrique. La originalidad de la copia: la CEPAL y la idea de desarrollo. Revista de la CEPAL. Santiago, n. 4, p. 7-40, 1977.

. La persistencia democrática. In: CARDOSO, Fernando Henrique et al. Medina Echavarría y la sociología latinoamericana. Madrid: Instituto de Cooperación Iberoamericana, 1982. p. 113-125.

CEPAL. El desarrollo social de América Latina en la postguerra. Buenos Aires: Solar-Hachette, 1963.

CEPÊDA, Vera Alves. Raízes do pensamento político de Celso Furtado: desenvolvimento, nacionalidade e Estado democrático. 1998. 254f. Dissertação (Mestrado em Ciência Política) Programa de Pós-Graduação em Ciência Política, Universidade de São Paulo, São Paulo, 1998.

DI FILIPPO, Armando. La Escuela Latinoamericana del Desarrollo: tensiones epistemológicas de movimiento fundacional. Santiago: Cinta de Moebio, n. 29, p. 124-154, 2007.

ECHAVARRÍA, José Medina. Aspectos sociales del desarrollo económico. Santiago: Editorial Andrés Bello, 1959a.

. El papel del sociólogo en las tareas del desarrollo económico. In:

(Org.). Aspectos sociales del desarrollo económico. Santiago: Editorial Andrés Bello, 1959b. p. 13-31.

. Las condiciones sociales del desarrollo económico. In: desarrollo económico. Santiago: Editorial Andrés Bello, 1959c. p. 33-68.

(Org.). Aspectos sociales del

. Consideraciones sociológicas sobre el desarrollo económico de América Latina. Buenos Aires:

Solar-Hachette, 1964.

. La universidad ante el desarrollo económico.

(Org.). Filosofía, educación y desarrollo. Cidade do México: Siglo XXI, 1967a. p. 172-236

Las relaciones entre las instituciones sociales y económicas. In: (Org.). Filosofía, educación y desarrollo. Cidade do México: Siglo XXI, p. 269-309, 1967 b.

. La planeación en las formas de la racionalidad. In:

(Org.). Discurso sobre política y planeación. Cidade do México: Siglo Ventiuno Editores, p. 98-176, 1972.

FALETTO, Enzo. Los temas de democracia y libertad en José Medina Echavarría: vigencia y contextos. In: CARDOSO, Fernando Hernique et al. Medina Echavarría y la sociología latinoamericana. Madrid: Instituto de Cooperación Iberoamericana (ICI), 1982. p. 127-135

FURTADO, Celso. Economia colonial no Brasil nos séculos XVI e XVII: elementos de história econômica aplicados à análise de problemas econômicos e sociais. São Paulo: Hucitec: ABPHE, 2001.

. A economia brasileira. Rio de Janeiro: A Noite, 1954.

. A pré-revolução brasileira. Rio de Janeiro: Fundo de Cultura, 1962.

. Dialética do desenvolvimento. Rio de Janeiro: Fundo de Cultura, 1964.

. Subdesenvolvimento e estagnação na América Latina. Rio de Janeiro: Civilização Brasileira, 1966.

Análise do "modelo" brasileiro. Rio de Janeiro: Civilização Brasileira, 1972.

Teoria e política do desenvolvimento econômico. Sáo Paulo: Editora Nacional, 1986.

. A fantasia organizada. In: D’AGUIAR, Rosa Freire (Org.). Obra autobiográfica de Celso Furtado. Sáo Paulo: Paz e Terra, v. 1. 1997a. p. 87-359.

A fantasia desfeita. In: D’AGUIAR, Rosa Freire (Org.). Obra autobiográfica de Celso Furtado. São Paulo: Paz e Terra v. 2. 1997b. p. 27-306. 
GURRIERI, Adolfo. Un perfil intelectual. In: ECHAVARRÍA, José Medina (Org.). La obra de José Medina Echavarría. Selección y estudio preliminar por A. Gurrieri. Madri: Instituto de Cooperación Iberoamericana, 1980.

LIMA, Marcos Costa. Uma concepção de mundo em Celso Furtado: ciência e perplexidade. In: LIMA, Marcos Costa, DAVID, Mauricio Dias (Org.). A atualidade do pensamento de Celso Furtado. São Paulo: Francis, 2008. p. 27-41.

LOVE, Joseph. Ideias e ideologias econômicas na América Latina, 1930-1990. In: BETHELL, Leslie

(Org.). História da América Latina: América Latina após 1930: Ideias, cultura e sociedade. São Paulo: Editora da Universidade de São Paulo, 2011. p. 161-242.

MANNHEIM, Karl. Diagnóstico de nosso tempo. Rio de Janeiro: Zahar, 1961.

Sociologia sistemática: uma introdução ao estudo da sociologia. São Paulo: Pioneira, 1962.

MARTÍN, Juan José Morales. José Medina Echavarría: vida y sociología. 2012. 994f. Tese (Doutorado em Sociologia) - Departamento de Sociología V (Teoría Sociológica), Facultad de Ciencias Políticas y Sociología, Universidad Complutense de Madrid, 2012.

REZENDE, Maria José. Celso Furtado e Karl Mannheim: uma discussão acerca do papel dos intelectuais nos processos de mudança social. Acta Scientiarum. Human and Social Sciences, Maringá, v. 26, n. 2, p. 239-250, 2004

VIANNA, Luiz Jorge Werneck. A institucionalização das ciências sociais e a reforma social: do pensamento social à agenda americana de pesquisa. In: (Org.). A revolução passiva: iberismo e americanismo no Brasil. Rio de Janeiro: Revan, 2004. p. 195-242.

VIEIRA, Rosa Maria. Celso Furtado: reforma, política e ideologia (1950-1964). Sáo Paulo: EDUC, 2007.

VIEIRA, Wilson. A construção da nação no pensamento de Celso Furtado. 2010. 241f. Tese (Doutorado em Sociologia) - Programa de Pós-Graduação em Sociologia, Universidade Estadual de Campinas, Campinas, 2010.

WEBER, Max. Economia e sociedade: fundamentos da sociologia compreensiva. Brasília: Editora da Universidade de Brasília, 2000. 